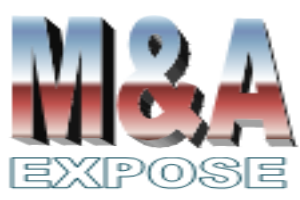

http://jurnal.usahid.ac.id/index .php/accounting
${ }^{1}$ Fakultas Komunikasi Bisnis Universitas Telkom gkarlina10@gmail.com

${ }^{2}$ Fakultas Komunikasi Bisnis Universitas Telkom ennosrini@gmail.com

\section{Pengaruh Green Marketing terhadap Keputusan Pembelian dengan Brand Image sebagai Mediator}

\author{
Gina Karlina ${ }^{1}$, Retno Setyorini ${ }^{2}$
}

\section{Abstrak}

Kerusakan yang terjadi pada lingkungan di Indonesia semakin parah sehingga kesadaran masyarakat akan pentingnya pelestarian lingkungan semakin meningkat. Kesadaran masyarakat tersebut mendorong produsen mulai beralih menggunakan bahan yang ramah lingkungan. Hal ini menimbulkan fenomena baru dalam dunia pemasaran yaitu berupa konsep green marketing. Salah satu brand yang menerapkan konsep green marketing yaitu Innisfree, brand asal Korea Selatan yang berfokus untuk menghasilkan produk kosmetik dan skin care yang berbahan dasar alami dan turut serta dalam pelestarian lingkungan. Tujuan penelitian ini untuk mengetahui pengaruh green marketing terhadap keputusan pembelian dengan brand image sebagai mediator, studi kasus pada Innisfree Bandung. Penelitian menggunakan metode kuantitatif dengan sampel 100 responden. Pengumpulan data melalui penyebaran kuesioner online kepada masyarakat di Bandung. Metode analisis yang digunakan adalah analisis desriptif dan path analysis. Penelitian ini menyimpulkan green marketing berpengaruh positif dan sigifikan terhadap brand image Innisfree, selanjutnya brand image dapat mendorong kepuusan pembelian.

Kata kunci : green marketing, brand image, keputusan pembelian.

\section{Abstract}

The environmental damage in Indonesia is getting worse. Therefore, public awareness about the importance of environmental preservation has also increased. It made producers start using ecofriendly materials. This creates a new phenomenon in marketing called a green marketing concept. One of the brands that applies the green marketing concept is Innisfree, a South Korean brand that focus on producing cosmetics and skin care products made from natural ingredients. The purpose of this study is to analyse the influence of green marketing on purchase decision with brand image as a mediator, case study of Innisfree Bandung. This research was conducted by using a quantitative method with 100 respondents. Data collection through the distribution of online questionares to the community in Bandung. The method of analysis used is descriptive analysis and path analysis. This research found that green marketing has a positive and significant effect on Innisfree's brand image, where brand image can encourage consumer purchase decision to buy Innisfree's products.

Keywords: green marketing, brand image, purchase decision. 


\section{PENDAHULUAN}

Kesadaran masyarakat akan pentingnya lingkungan kian meningkat seiring bertambahnya tingkat kerusakan lingkungan khususnya di Indonesia. Kesadaran masyarakat tentang pentingnya menjaga lingkungan ditandai dengan beberapa warga yang kini sudah mulai menggunakan atau membawa kantong belanja sendiri saat berbelanja untuk mengurangi pemakaian plastik (Kompas.com., 2016).

Bagi pelaku usaha hal tersebut dapat dijadikan sebagai peluang untuk memeuhi kebutuhan dan keinginan masyarakat, dengan beralih menggunakan bahan baku yang alami dan ramah lingkungan dalam pembuatan produk maupun kemasannya. Upaya tersebut dikenal dengan istilah green marketing. Green marketing terdiri dari seluruh aktivitas suatu perusahaan yang bertujuan untuk menghasilkan dan memenuhi kebutuhan konsumen dengan mengurangi seminimal mungkin dampak kerusakan pada lingkungan (Verma dan Tanwar, 2014:1).

Beberapa sektor industri saat ini sudah banyak yang mulai beralih pada konsep green marketing misalnya dengan membuat produknya yang berbahan baku alami, proses produksi yang tidak mencemari lingkungan sekitar, maupun menggunakan kemasan yang dapat didaur ulang. Namun industri yang paling menonjol dalam hal green marketing yaitu industri kosmetik karena industri kosmetik selalu konsisten mengalami peningkatan dibandingkan industri lainnya dan berperan besar sebagai penggerak utama perekonomian (CNN Indonesia.com, 2016).

Wanita Indonesia lebih menyukai produk kosmetik yang berasal dari Korea terbukti dengan hasil survei ZAP Beauty Index 2018 yang melibatkan 17.889 wanita Indonesia bahwa wanita Indonesia paling suka produk asal Korea sejumlah $40 \%$, lalu diikuti oleh produk Indonesia 34\%, dan produk asal Jepang 21\% (kolom.kontan.id, 2018).

Menurut Direktur The Saem Indonesia, brand asal Korea Selatan ini disukai oleh wanita Indonesia dikarenakan produk kosmetik asal Korea merupakan produk yang ramah lingkungan dan berbahan baku alami (lifestyle.kompas.com, 2018).

Salah satu perusahaan yang menerapkan konsep green marketing adalah Innisfree. Innisfree merupakan brand asal Korea Selatan yang berfokus untuk menghasilkan produk kosmetik dan skin care yang berbahan dasar alami juga turut serta dalam pelestarian lingkungan.

\section{TINJAUAN PUSTAKA}

Tujuan penelitian ini adalah untuk mengetahui pengaruh green marketing terhadap keputusan pembelian melalui brand image sebagai mediator. Dimana green marketing merupakan upaya-upaya stratejik yang dilakukan oleh suatu perusahaan dalam menyediakan produk/jasa yang ramah lingkungan kepada target konsumen (Grewal dan Levy; Aldoko et al., 2016).

Brand image adalah sejumlah keyakinan tentang merek yang melekat dalam ingatan konsumen (Riyanti dan Budiatmo, 2017). Keputusan didefinisikan sebagai pemilihan suatu tindakan yang berasal dari dua atau lebih pilihan alternatif (Priansa, 2017). 


\section{METODE PENELITIAN}

Metode penelitian yang digunakan pada penelitian ini adalah metode penelitian kuantitatif dan analisis deskriptif dengan menggunakan path analysis. Adapun metode pengumpulan datanya adalah sebagai berikut :

1. Kuesioner (angket) : kuesioner disebarkan secara online dalam bentuk google form melalui media sosial kepada masyarakat di Bandung.

2. Studi pustaka : studi pustaka dilakukan dengan mempelajari, menelaah, dan mengkaji berbagai literatur berupa buku, jurnal, penelitian terdahulu.

Skala pengukuran yang digunakan pada penelitian ini adalah Skala Likert. Skala Likert merupakan skala yang digunakan untuk mengukur sikap, pendapat, dan persepsi seseorang pada fenomena tertentu (Sugiyono, 2017). Kuesioner diajukan dengan menggunakan Skala Likert meliputi angka 1 sampai 5, seperti berikut :

1 = sangat tidak setuju

2 = setuju

$3=$ kurang setuju

$4=$ setuju

5 = sangat setuju

Definisi operasional variabel penelitian ini sebagai berikut :

Tabel 1. Variabel Operasional

\begin{tabular}{|c|c|c|c|c|}
\hline Variabel & Dimensi & Indikator & Skala & No. Item \\
\hline \multirow{11}{*}{$\begin{array}{c}\text { Green } \\
\text { Marketing } \\
\text { (Kotler \& } \\
\text { Amstrong, } \\
\text { 2001) }\end{array}$} & \multirow[t]{2}{*}{ Green Product } & $\begin{array}{l}\text { 1. Kemasan mengindikasikan } \\
\text { produk ramah lingkungan }\end{array}$ & Ordinal & 1 \\
\hline & & $\begin{array}{l}\text { 2. Kemasan dapat didaur } \\
\text { ulang. }\end{array}$ & Ordinal & 2 \\
\hline & \multirow[t]{3}{*}{ Green Price } & $\begin{array}{l}\text { 1. Harga dibanding produk } \\
\text { sejenis lainnya }\end{array}$ & Ordinal & 3 \\
\hline & & $\begin{array}{l}\text { 2. Harga sesuai dengan } \\
\text { kinerja }\end{array}$ & Ordinal & 4 \\
\hline & & $\begin{array}{l}\text { 3. Harga sesuai dengan } \\
\text { desain }\end{array}$ & Ordinal & 5 \\
\hline & \multirow[t]{4}{*}{$\begin{array}{c}\text { Green } \\
\text { Promotion }\end{array}$} & $\begin{array}{l}\text { 1. Memberikan pesan } \\
\text { lingkungan melalui iklan }\end{array}$ & Ordinal & 6 \\
\hline & & $\begin{array}{l}\text { 2. Memberikan pesan } \\
\text { lingkungan melalui media } \\
\text { sosial }\end{array}$ & Ordinal & 7 \\
\hline & & $\begin{array}{l}\text { 3. Memberikan pesan } \\
\text { lingkungan melalui } \\
\text { kampanye }\end{array}$ & Ordinal & 8 \\
\hline & & 4. Memotivasi konsumen & Ordinal & 9 \\
\hline & \multirow[t]{2}{*}{ Green Place } & 1. Gerai mudah dijangkau & Ordinal & 10 \\
\hline & & $\begin{array}{l}\text { 2. Produk tersedia dengan } \\
\text { lengkap }\end{array}$ & Ordinal & 11 \\
\hline
\end{tabular}




\begin{tabular}{|c|c|c|c|c|}
\hline Variabel & Dimensi & Indikator & Skala & No. Item \\
\hline \multirow{8}{*}{$\begin{array}{l}\text { Brand Image } \\
\text { (Kotler \& } \\
\text { Keller, 2016) }\end{array}$} & $\begin{array}{l}\text { Strength of } \\
\quad \text { brand }\end{array}$ & $\begin{array}{l}\text { 1. Posisi brand di benak } \\
\text { konsumen }\end{array}$ & Ordinal & 12 \\
\hline & Favourable of & 1. Kualitas produk & Ordinal & 13 \\
\hline & brand & 2. Variasi produk & Ordinal & 14 \\
\hline & association & 3. Brand mudah dikenali & Ordinal & 15 \\
\hline & & 4. Brand mudah diingat & Ordinal & 16 \\
\hline & Uniqueness of & 1. Perbandingan harga & Odinal & 17 \\
\hline & $\begin{array}{c}\text { brand } \\
\text { association }\end{array}$ & $\begin{array}{l}\text { 2. Perbandingan kualitas } \\
\text { produk }\end{array}$ & Ordinal & 18 \\
\hline & & 3. Keunikan produk & Ordinal & 19 \\
\hline \multirow{12}{*}{$\begin{array}{l}\text { Keputusan } \\
\text { Pembelian } \\
\text { (Kotler \& } \\
\text { Amstrong, } \\
\text { 2016) }\end{array}$} & Pilihan produk & $\begin{array}{l}\text { 1. Sesuai dengan kebutuhan } \\
\text { konsumen }\end{array}$ & Ordinal & 20 \\
\hline & & $\begin{array}{l}\text { 2. Sesuai dengan keinginan } \\
\text { konsumen }\end{array}$ & Ordinal & 21 \\
\hline & & 3. Penilaian alternatif & Ordinal & 22 \\
\hline & Pilihan merek & $\begin{array}{l}\text { 1. Posisi produk dengan } \\
\text { brand lainnya }\end{array}$ & Ordinal & 23 \\
\hline & & 2. Pilihan alternatif & Ordinal & 24 \\
\hline & Pilihan & 1. Lokasi gerai & Ordinal & 25 \\
\hline & penyalur & 2. Suasana gerai & Ordinal & 26 \\
\hline & $\begin{array}{c}\text { Metode } \\
\text { pembayaran }\end{array}$ & $\begin{array}{l}\text { 1. Metode Pembayaran } \\
\text { secara tunai }\end{array}$ & Ordinal & 27 \\
\hline & & $\begin{array}{l}\text { 2. Metode Pembayaran } \\
\text { secara tunai }\end{array}$ & Ordinal & 28 \\
\hline & & $\begin{array}{l}\text { 3. Metode Pembayaran } \\
\text { secara tunai }\end{array}$ & Ordinal & 29 \\
\hline & $\begin{array}{l}\text { Waktu } \\
\text { Pembelian }\end{array}$ & 1. Pemilihan waktu pembelian & Ordinal & 30 \\
\hline & $\begin{array}{l}\text { Jumlah } \\
\text { pembelian }\end{array}$ & $\begin{array}{l}\text { 1. Jumlah produk yang } \\
\text { dibelanjakan }\end{array}$ & Ordinal & 31 \\
\hline
\end{tabular}

Populasi adalah wilayah generalisasi yang terdiri atas obyek/subyek yang mempunyai kualitas dan karakteristik tertentu yang ditetapkan oleh peneliti untuk diteliti (Sugiyono, 2017). Populasi dalam penelitian ini adalah masyarakat di Bandung yang mengetahui produk Innisfree.

Sampel merupakan bagian dari jumlah dan karakteristik pada populasi tersebut (Sugiyono, 2017). Sampel yang digunakan pada penelitian ini adalah perempuan yang mengetahui produk Innisfree. Mengingat jumlah populasi pada penelitian ini tidak diketahui jumlahnya dengan pasti, maka untuk menentukan sampel penulis menggunakan teknik sampel dengan menggunakan rumus Bernoulli berikut : (Indrawan dan Yaniawati, 2014).

$$
n \geq \frac{\left[z \frac{a}{2}\right]^{2} p \cdot q}{e^{2}}
$$


Keterangan :

$n=$ jumlah sampel minimum

$a=$ tingkat ketelitian

$z=$ nilai standar distribusi normal

$p=$ probabilitas ditolak

$q=$ probabilitas diterima $(1-p)$

$e=$ tingkat kesalahan

Dalam penelitian ini digunakan tingkat ketelitian (a) 5 persen, tingkat kepercayaan 95 persen sehingga diperoleh nilai $Z=1,96$. Tingkat kesalahan ditentukan sebesar 10 persen. Sementara itu, probabilitas kuesioner benar (diterima) atau salah (ditolak) masing-masing adalah 0,5. Dengan memasukan ke dalam persamaan rumus sampel, maka:

$$
\begin{aligned}
& n \geq \frac{[1,96]^{2} 0,5 \cdot 0,5}{0,1^{2}} \\
& n \geq \frac{0,9604}{0,01} \\
& n \geq 96,04
\end{aligned}
$$

Berdasarkan perhitungan di atas, maka sampel minimal yang digunakan pada penelitian ini adalah 96,04 namun dibulatkan menjadi 100 responden. Dalam penelitian ini menggunakan teknik sampling nonprobability sampling dengan teknik sampel purposive sampling.

\section{HASIL DAN PEMBAHASAN}

Karakteristik Responden. Berdasarkan hasil penelitian yang dilakukan terhadap 100 responden yang mengetahui brand Innisfree di Bandung, mayoritas berjenis kelamin perempuan berusia 20-29 tahun, berprofesi sebagai pegawai swasta, dan rata-rata mengeluarkan uang belanja kosmetik atau skin care perbulan sebesar $R p$ 600.000-Rp 900.000. Jika dilihat dari hasil karakteristik responden tersebut, dapat diketahui bahwa target market dari Innisfree merupakan perempuan usia muda hingga dewasa kelas menengah. Seperti pada penelitian yang dilakukan oleh Kim (2013) menyebutkan bahwa target market dari Innisfree adalah perempuan kelas menengah dengan usia 20-29 tahun.

Analisis Deskriptif. Variabel green marketing secara keseluruhan pada garis kontinum termasuk dalam kategori "Baik". Dengan presentase 77,3 persen yang berarti ratarata responden menilai bahwa pelaksanaan green marketing yang terdiri dari dimensi green product, green price, green promotion, dan green place yang dilakukan oleh Innisfree sudah dilakukan dengan baik.

Variabel brand image secara keseluruhan pada garis kontinum termasuk dalam kateg ori "Baik". Dengan presentase 77,1 persen yang berarti bahwa rata-rata responden menilai bahwa brand image dari Innisfree yang terdiri dari dimensi strength of brand, favourable of brand association, dan uniqueness of brand association sudah baik. Artinya brand image Innisfree sebagai brand yang ramah lingkungan di mata konsumen sudah baik.

Variabel keputusan pembelian secara keseluruhan pada garis kontinum termasuk dalam kategori "Baik". Dengan presentase 77,7 persen yang berarti responden menilai bahwa keputusan pembelian yang terdiri dari dimensi pilihan produk, pilihan merek, pilihan 
penyalur, waktu pembelian, jumlah pembelian, dan metode pembayaran pada Innisfree dapat dikatakan baik. Artinya konsumen memiliki keinginan cukup tinggi untuk membeli produk Innisfree.

Tabel 2. Uji Normalitas

\begin{tabular}{ccr}
\hline & & Unstandardized Residual \\
\hline Normal Parameters & & 100 \\
& Mean & \\
& Std. & 0000000 \\
Most Extreme & Absolute &, 09850667 \\
Differences & Positive &, 073 \\
& Negative &, 070 \\
Test Statistic &,- 073 \\
Asymp. Sig. (2-tailed) &, 073 \\
a. Test distribution is Normal. &, $200^{\mathrm{c}, \mathrm{d}}$ \\
\hline b. Calculated from data. & \\
c. Lilliefors Significance Correction. \\
d. This is a lower bound of the true significance. \\
\hline Sumber : Data diolah
\end{tabular}

Berdasarkan tabel 2 dapat dilihat bahwa nilai sig berada diatas $0,05(0,200>0,05)$. Dengan demikian dapat dikatakan bahwa model regresi berdistribusi normal.

Tabel 3. Uji Linearitas

\begin{tabular}{|c|c|c|c|c|c|c|c|}
\hline & & & $\begin{array}{l}\text { Sum of } \\
\text { Squares }\end{array}$ & df & $\begin{array}{l}\text { Mean } \\
\text { Square }\end{array}$ & $F$ & Sig. \\
\hline$(\mathrm{Y})$ & Between & (Combined) & 2,038 & 59 & ,035 & 3,568 & ,000 \\
\hline \multirow[t]{4}{*}{${ }^{*}(X)$} & Groups & Linearity & 1,359 & 1 & 1,359 & 140,340 &, 000 \\
\hline & & $\begin{array}{l}\text { Deviation from } \\
\text { Linearity }\end{array}$ & ,679 & 58 & ,012 & 1,210 & 264 \\
\hline & Wit & in Groups & ,387 & 40 & ,010 & & \\
\hline & & Total & 2,425 & 99 & & & \\
\hline
\end{tabular}

Sumber : Data diolah

Berdasarkan tabel 3 didapat nilai deviation from linearity sebesar 0,264, yang berarti lebih besar dari 0,05. Maka dapat dikatakan bahwa data tersebut linier.

Analisis Jalur (Path Analysis). Persamaan jalur yang diperoleh berdasarkan hasil analisis SPSS dirumuskan menjadi sub struktur 1 dan sub struktur 2 sebagai berikut :

Sub Struktur 1 :

$Z=$ Green Marketing 
Pengaruh Green Marketing terhadap Keputusan Pembelian ....

Gina Karlina, Retno Setyorini

Tabel 4. Pengaruh Green Marketing Terhadap Brand Image

\begin{tabular}{|c|c|c|c|c|c|c|}
\hline \multicolumn{7}{|c|}{ Coefficients $^{a}$} \\
\hline & \multirow{2}{*}{ Model } & \multicolumn{2}{|c|}{$\begin{array}{l}\text { Unstandardized } \\
\text { Coefficients }\end{array}$} & \multirow{2}{*}{$\begin{array}{c}\text { Standardized } \\
\text { Coefficients } \\
\text { Beta }\end{array}$} & \multirow{2}{*}{$\mathrm{t}$} & \multirow{2}{*}{ Sig. } \\
\hline & & B & Std. Error & & & \\
\hline \multirow[t]{2}{*}{1} & (Constant) & 1,530 & 193 & & 7,922 & .000 \\
\hline & Green Marketing (X) & 475 & ,060 & 625 & 7,932 & ,000 \\
\hline
\end{tabular}

a. Dependent Variable: Brand Image (Z)

Sumber : Data diolah

Berdasarkan tabel 4, dapat diketahui bahwa arah hubungan Green Marketing (X) dengan Brand Image (Z) adalah positif. Nilai pada kolom standardized coefficients beta tertulis 0,625 artinya ketika ada peningkatan Green Marketing (X) maka akan meningkatkan Brand Image (Z). Untuk mengetahui pengaruh variabel bebas terhadap variabel terikat maka dilakukan uji hipotesis parsial atau uji t dengan hipotesis sebagai berikut :

$\mathrm{H}_{0} \quad$ : Green Marketing (X) tidak berpengaruh signifikan terhadap Brand Image (Z) produk Innisfree di Kota Bandung.

$\mathrm{H}_{1}$ : Green Marketing $(\mathrm{X})$ berpengaruh signifikan terhadap Brand Image (Z) produk Innisfree di Kota Bandung.

Berdasarkan ketentuan yang telah dikemukakan sebelumnya, dimana diperoleh thitung sebesar 7,932 dan derajat bebas $(n-k-1)$ atau 100-1-1 = 98 diperoleh angka t tabel 1,984, sehingga t-hitung > t-tabel. Artinya $\mathrm{H}_{0}$ ditolak dan $\mathrm{H}_{1}$ diterima, maka Green Marketing (X) berpengaruh signifikan terhadap Brand Image (Z) produk Innisfree di Wilayah Bandung.

\section{Substruktur 2}

$Y=$ Green Marketing + Brand Image

Tabel 5. Pengaruh Green Marketing dan Brand Image Terhadap Keputusan Pembelian

\begin{tabular}{|c|c|c|c|c|c|c|}
\hline \multicolumn{7}{|c|}{ Coefficients $^{a}$} \\
\hline \multirow{2}{*}{\multicolumn{2}{|c|}{ Model }} & \multicolumn{2}{|c|}{$\begin{array}{l}\text { Unstandardized } \\
\text { Coefficients }\end{array}$} & \multirow{2}{*}{$\begin{array}{c}\text { Standardized } \\
\text { Coefficients } \\
\text { Beta }\end{array}$} & \multirow[t]{2}{*}{$\mathrm{t}$} & \multirow[t]{2}{*}{ Sig. } \\
\hline & & B & Std. Error & & & \\
\hline \multirow[t]{3}{*}{1} & (Constant) & ,833 & ,238 & & 3,702 & ,000 \\
\hline & Green Marketing (X) & ,359 & , 074 & 450, & 4,847 & , 000 \\
\hline & Brand Image (Z) & ,340 & ,097 & ,324 & 3,491 & ,001 \\
\hline
\end{tabular}

a. Dependent Variable: Keputusan Pembelian (Y)

Sumber : Data diolah

Berdasarkan tabel 5 dapat diketahui bahwa arah hubungan Green Marketing (X) dengan Keputusan Pembelian (Y) adalah positif. Nilai pada kolom standardized coefficients beta tertulis 0,450 artinya ketika ada peningkatan Green Marketing $(\mathrm{X})$ maka akan meningkatkan Keputusan Pembelian (Y). Arah hubungan Brand Image (Z) dengan Keputusan Pembelian $(Y)$ adalah positif, nilai pada kolom standardized coefficients beta tertulis 0,324 artinya ketika ada peningkatan Brand Image (Z) maka akan meningkatkan Keputusan Pembelian (Y). 
Untuk mengetahui pengaruh variabel bebas terhadap variabel terikat maka dilakukan uji hipotesis parsial atau uji t dengan hipotesis sebagai berikut:

a. Pengaruh Green Marketing terhadap Keputusan Pembelian :

$\mathrm{H}_{0} \quad$ : Green Marketing (X) tidak berpengaruh signifikan terhadap Keputusan Pembelian (Y) produk Innisfree di Kota Bandung.

$\mathrm{H}_{1} \quad$ : Green Marketing (X) berpengaruh signifikan terhadap Keputusan Pembelian ( $\mathrm{Y}$ ) produk Innisfree di Kota Bandung.

Berdasarkan ketentuan yang telah dikemukakan sebelumnya, di mana diperoleh t-hitung sebesar 4,847 dan derajat bebas (n-k-1) atau 100-1-1 = 98 diperoleh angka t tabel 1,984, sehingga t-hitung $>$ t-tabel. Artinya $\mathrm{H}_{0}$ ditolak dan $\mathrm{H}_{1}$ diterima, maka Green Marketing $(\mathrm{X})$ berpengaruh signifikan terhadap Keputusan Pembelian (Y) produk Innisfree di Wilayah Bandung.

b. Pengaruh Brand Image terhadap Keputusan Pembelian :

$\mathrm{H}_{0}$ : Brand Image (Z) tidak berpengaruh signifikan terhadap Keputusan Pembelian ( $\mathrm{Y}$ ) produk Innisfree di Kota Bandung.

$\mathrm{H}_{1}$ : Brand Image $(\mathrm{Z})$ berpengaruh signifikan terhadap Keputusan Pembelian ( $\mathrm{Y}$ ) produk Innisfree di Kota Bandung.

Berdasarkan ketentuan yang telah dikemukakan sebelumnya, di mana diperoleh t-hitung sebesar 3,491 dan derajat bebas (n-k-1) atau 100-1-1 = 98 diperoleh angka t tabel 1,984, sehingga t-hitung > t-tabel. Artinya $\mathrm{H}_{0}$ ditolak dan $\mathrm{H}_{1}$ diterima, maka Brand Image $(\mathrm{Z})$ berpengaruh signifikan terhadap Keputusan Pembelian $(\mathrm{Y})$ produk Innisfree di Wilayah Bandung.

c. Pengaruh Green Marketing terhadap Keputusan Pembelian melalui Brand Image :

$\mathrm{H}_{0} \quad$ : Green Marketing (X) tidak berpengaruh signifikan terhadap Keputusan Pembelian (Y) melalui Brand Image (Z) produk Innisfree di Kota Bandung.

$\mathrm{H}_{1} \quad$ : Green Marketing (X) berpengaruh signifikan terhadap Keputusan Pembelian ( $\mathrm{Y}$ ) melalui Brand Image (Z) produk Innisfree di Kota Bandung.

Berdasarkan perhitungan yang uji sobel, diperoleh nilai t thitung adalah 3,185 . Karena nilai t hitung nya $(3,185)>\mathrm{t}$ tabel $(1,984)$ maka $\mathrm{H}_{0}$ ditolak, artinya Green Marketing $(\mathrm{X})$ berpengaruh signifikan terhadap Keputusan Pembelian (Y) melalui Brand Image (Z) produk Innisfree di Wilayah Bandung.

Pengaruh Langsung dan Tidak Langsung. Besaran pengaruh langsung dan tidak langsung dari variabel independen terhadap variabel dependen adalah sebagaimana tabel berikut :

Tabel 6. Pengaruh Langsung dan Tidak Langsung

\begin{tabular}{ccccc}
\hline \multirow{2}{*}{ Variabel } & Koefisien Jalur & \multicolumn{2}{c}{ Pengaruh } & \multirow{2}{*}{ Pengaruh Total } \\
\cline { 3 - 4 } & & Langsung & Tidak Langsung & \\
\hline$X \rightarrow Z$ & 0,625 & $39,1 \%$ & & $39,1 \%$ \\
$X \rightarrow Y$ & 0,450 & $20,34 \%$ & $20,25 \%$ & $40,59 \%$ \\
$Z \rightarrow Y$ & 0,324 & $10,15 \%$ & & $10,15 \%$ \\
\hline
\end{tabular}

Sumber : Data diolah

Tabel 6 menjelaskan mengenai besar pengaruh dari masing-masing variabel. Dari tabel di atas, dapat dijabarkan bahwa: 
a. Green Marketing $(\mathrm{X})$ berpengaruh langsung terhadap Keputusan Pembelian $(\mathrm{Y})$ sebesar 39,1 persen.

b. Green Marketing ( $\mathrm{X}$ ) berpengaruh langsung terhadap Keputusan Pembelian ( $\mathrm{Y}$ ) sebesar 20,34 persen dan pengaruh tidak langsung terhadap Keputusan Pembelian (Y) melalui Brand Image (Z) sebesar 20,25 persen. Total pengaruh Green Marketing (X) terhadap Keputusan Pembelian ( $\mathrm{Y}$ ) adalah sebesar 49,59 persen.

c. Brand Image ( $\mathrm{Z}$ ) berpengaruh langsung terhadap Keputusan Pembelian ( $\mathrm{Y}$ ) sebesar 10,15 persen.

\section{KESIMPULAN}

Berdasarkan analisis hasil penelitian dan pembahasan yang telah diuraikan maka dapat diperoleh kesimpulan sebagai berikut :

1. Green marketing yang dilakukan oleh Innisfree termasuk kategori baik artinya sebagian besar responden beranggapan bahwa kegiatan green marketing yang dilakukan Innisfree sudah baik. Nilai tertinggi terdapat pada dimensi green place yang berarti bahwa gerai Innisfree cukup mudah dijangkau dan produk yang tersedia di gerai lengkap. Sedangkan nilai terendah terdapat pada dimensi green product yang berarti bahwa produk Innisfree kurang mengindikasikan sebagai produk yang ramah lingkungan.

2. Brand image Innisfree termasuk dalam kategori baik, artinya sebagian besar responden beranggapan bahwa brand image Innisfree sebagai brand yang ramah lingkungan suah baik. Nilai tertinggi terdapat pada dimensi strength of brand, yang berarti rata-rata konsumen setuju bahwa Innisfree merupakan merek kosmetik yang ramah lingkungan. Sedangkan nilai terendah terdapat pada dimensi favourable of brand association, yang berarti bahwa brand Innisfree kurang mudah diingat oleh konsumen.

3. Keputusan pembelian Innnisfree termasuk dalam kategori baik dengan nilai tertinggi terdapat pada dimensi waktu pembelian, yang berarti rata-rata konsumen membeli produk Innisfree secara rutin. Sedangkan nilai terendah terdapat pada dimensi pilihan penyalur yang berarti bahwa lokasi gerai Innisfree yang mudah dijangkau dan suasana pada gerai Innisfree kurang mendorong konsumen untuk berbelanja produk Innisfree.

4. Green marketing berpengaruh terhadap keputusan pembelian dengan nilai positif dan signifikan, maka ketika ada peningkatan Green Marketing $(\mathrm{X})$ maka akan meningkatkan Keputusan Pembelian (Y).

5. Green marketing berpengaruh positif secara signifikan terhadap brand image, maka peningkatan Green Marketing (X) akan meningkatkan Brand Image (Z).

6. Brand image berpengaruh positif secara signifikan terhadap keputusan pembelian, maka peningkatan Brand Image (Z) akan meningkatkan Keputusan Pembelian (Y).

7. Brand image dapat menjadi mediator untuk mempengaruhi keputusan pembelian konsumen dalam kegiatan green marketing yang dilakukan oleh Innisfree.

Berdasarkan penelitian yang telah dilakukan, dikemukakan saran sebagai berikut:

1. Innisfree agar merevisi desainnya menggunakan warna yang mencerminkan produk ramah lingkungan seperti warna hijau atau coklat, menambah aksen daun-daun, dan lain lain. Dengan demikian, diharapkan dengan melihat kemasan produknya saja, konsumen dapat menilai bahwa Innisfree merupakan brand kosmetik dan skin care yang ramah lingkungan. 
2. Innisfree agar meningkatkan kemampuan merek agar lebih mudah diingat konsumen dengan meningkatkan komunikasi pemasaran atau promosi pada media sosial, iklan pada siaran televisi, dan meningkatkan penyebaran brosur. Selain itu, dapat meningkatkan kerja sama dengan public figure, karena biasanya apa yang dipakai oleh public figure akan menjadi perhatian konsumen.

3. Innisfree agar meningkatkan suasana gerai. Suasana yang dimaksud adalah dalam arti atmosfer yang tercipta dari gabungan unsur-unsur desain toko/gerai, perencanaan toko, komunikasi visual, dan merchandising.

4. Innisfree agar mengembangkan lagi kegiatan green marketing dan brand image, misalnya dengan meningkatkan kampanye agar konsumen dapat lebih berkontribusi secara langsung misalnya dengan penanaman pohon, dan lain-lain. Juga akan lebih baik apabila Innisfree meningkatkan komunikasi pemasarannya untuk menekankan bahwa Innisfree merupakan produk yang ramah lingkungan, sehingga konsumen akan lebih aware terhadap brand image Innisfree sebagai brand yang ramah lingkungan. Kegiatan green marketing yang baik tentunya akan meningkatkan brand image Innisfree sebagai brand yang ramah lingkungan, dan brand yang baik akan meningkatkan keputusan pembelian.

\section{DAFTAR PUSTAKA}

Indrawan, R. \& Yaniawati R.P. 2014. Metodologi Penelitian Kuantitatif, Kualitatif, dan Campuran Untuk Manajemen, Pembangunan, dan Pendidikan. Bandung : PT Refika Aditama.

Sugiyono. 2017. Metode Penelitian Kuantitatif, Kualitatif, dan R\&D. Bandung: Alfabeta.

Priansa, D.P. 2017. Perilaku Konsumen dalam Bisnis Kontemporer. Bandung: Alfabeta

Rianti, A. dan Budiatmo, A. 2017. Pengaruh Brand Image dan Kualitas Produk terhadap Keputusan Pembelian (Studi Kasus Pada Konsumen Carica Gemilang Di Wonosobo). Vol 6, No. 3, p.1-11.

Aldoko, D.S. Suharyano dan Yulianto, E. 2016. Pengaruh Green Marketing Terhadap Citra Merek dan Dampaknya Terhadap Keputusan Pembelian. Jurnal Administrasi Bisnis. Vol 40, No. 2, p.17-23.

Verma, A. dan Tanwar R. 2014. Green Marketing: The Revolutionary Road. International Journal of Business and Management Invention. Volume 3, p.01-06.

Kim Ji Hyun. 2013. Marketing Presentation Innisfree diakses pada 15 Januari 2019 dari : https://prezi.com/nle3a5bjd9xk/marketing-presentation-innisfree/

Khoiri, A. 2019. Industri Kosmetik Unjuk Gigi Di Beauty Indonesia diakses pada 16 Januari 2019 dari : https://www.cnnindonesia.com/qaya-hidup/20160616141900-277138615/industri-kosmetik-unjuk-gigi-di-beautyindonesia-

Wulandhari, R. 2019. Perempuan Indonesia Lebih Suka Pakai Produk Kecantikan Korea. diakses pada 15 Januari 2019 dari : https://www.republika.co.id/berita/gayahidup/trend/18/10/06/pg5nxz328-perempuan-indonesia-lebih-suka-pakai-produkkecantikan-korea-

Tashandra, N. 2019. Kosmetik Ramah Lingkungan Lebih Disukai. diakses pada 15Januari 2019 dari : (https://lifestyle.kompas.com/read/2018/07/17/153800920/kosmetik-ramahlingkungan-lebih-disukai 